\title{
pH Evaluation over a Period of 6 months of Two-bottle Water-based Self-etching Primers: An In Vitro Study
}

\author{
Antonio Signore ${ }^{1}$, Nicola De Angelis ${ }^{2}$, Nicolò Di Tullio ${ }^{3}$, Andrea Amaroli ${ }^{4}$, Luca Solimei ${ }^{5}$
}

\begin{abstract}
Aim and objective: The objective of this study was to monitor the pH stability over a period of 6 months of two-bottle self-etching (SE) primers. Materials and methods: Four commercially available two-bottle SE primer solutions, Adhese SE (Ivoclar Vivadent; Schaan, Liechtenstein), Clearfil SE (Kuraray; Tokyo, Japan), Contax Primer (DMG; Hamburg, Germany), and Enabond SE (Micerium; Avegno (Ge), Italy), containing water as the main solvent were selected. The $\mathrm{pH}$ values during a 6 -month storage period at intermittent temperature were daily measured by means of a microprocessor-based $\mathrm{pH} /$ temperature meter and hence recorded, tabulated, and analyzed.

Results: The mean values of overall pH measurements and standard deviation for Adhese SE, Clearfil SE, Contax Primer, and Enabond SE are, respectively, $1.70( \pm 0.01), 1.72( \pm 0.01), 1.20( \pm 0.01), 1.80( \pm 0.01)$. One-way ANOVA did not detect any significant change of the mean $\mathrm{pH}$ values of all measurements over time.

Conclusion: The conventional 6-months storage did not affect the $\mathrm{pH}$ values of the water-containing primers of two-bottle SE adhesives.

Clinical significance: This study provides evidence that conventional storage under adequate conditions did not affect the $\mathrm{pH}$ values of the water-containing primers of two-bottle SE adhesives with different monomer formulations. Clinicians may rely on the known $\mathrm{pH}$ value of the selected SE adhesive during shelf-life.

Keywords: Adhesive, pH, Primers, Self-etching.

The Journal of Contemporary Dental Practice (2021): 10.5005/jp-journals-10024-3172
\end{abstract}

\section{INTRODUCTION}

The strategy of self-etching (SE) adhesives is to simultaneously etch and prime enamel and dentin, integrating the dissolved smear layer and the partially demineralized tissues into the adhesive interface. ${ }^{1,2}$ Currently SE adhesives are applied in single-step or two-steps, depending on the treatment modalities employed by the manufacturers. ${ }^{3}$ The degree of enamel and dentin demineralization is dependent on the $\mathrm{pH}$ of the priming solution, which is related to the composition and concentration of the acids and/or polymerizable acidic resin monomers. ${ }^{2}$ In addition, the type of solvents and co-monomers plays a major role, as they affect the film forming properties and adhesive strength. ${ }^{4}$

A well-established classification for SE adhesives is according to their acidity. ${ }^{1,5}$ The $\mathrm{pH}$ value of the most SE primers ranges between 0.4 and 2.6, higher than that of the conventional $37 \%$ phosphoric acid (around 0.5). 1,3,6,7 The aggressiveness of the SE adhesives has been classified based on the extent of hybridization at the dentinadhesive interface. The SE adhesives have been graded as strong $(\mathrm{pH} \leq 1)$, exhibiting a hybrid layer of some micrometers in depth; intermediately strong or moderate $(\mathrm{pH}: 1-2)$, possessing a hybrid layer depth of 1-2 $\mu \mathrm{m}$; mild ( $\mathrm{pH}$ : 2-2.5), demonstrating an $\sim \mu \mathrm{m}$ hybrid layer of ultra-mild ( $\mathrm{pH}>2.5)$, with a nanosized hybrid layer. ${ }^{1,8}$ Since recent studies have critically pointed out the vulnerable stability of SE adhesives as an intrinsic disadvantage, a shelf-life evaluation has been advocated to be fundamental to verify the materials' behavior over time. ${ }^{9,10}$ To the authors' knowledge, there is no information about any possible $\mathrm{pH}$ variation of these adhesives during shelf-life. Thus, the aim of the present investigation was to monitor the stability of the $\mathrm{pH}$ values of water-containing primers of two-step SE adhesive systems during a 6-month storage period at $4^{\circ} \mathrm{C}$. The first null hypothesis tested was that the $\mathrm{pH}$ changes during the storage period. The second null hypothesis tested
${ }^{1}$ Department of Therapeutic Stomatology, Institute of Dentistry, IM Sechenov First Moscow State Medical University, Moscow, Russian Federation

2,3,5 Department of Surgical Science and Integrated Diagnostics (DISC), University of Genova, Genova, Italy

${ }^{4}$ Department of Orthopaedic Dentistry, IM Sechenov First Moscow State Medical University, Moscow, Russian Federation

Corresponding Author: Antonio Signore, Department of Therapeutic Stomatology, Institute of Dentistry, IM Sechenov First Moscow State Medical University, Moscow, Russian Federation, Phone: +39063721645, e-mail: dr.signore@icloud.com

How to cite this article: Signore A, De Angelis N, Di Tullio N, et al. pH Evaluation over a Period of 6 months of Two-bottle Water-based Self-etching Primers: An In Vitro Study. J Contemp Dent Pract 2021;22(8):856-859.

Source of support: Nil

Conflict of interest: None

was that $\mathrm{pH}$ variation during storage period differs between the materials tested.

\section{Materials and Methods}

Four commercially available two-bottle SE adhesives, Adhese SE (Ivoclar Vivadent; Schaan, Liechtenstein), Clearfil SE (Kuraray; Tokyo, Japan), Contax Primer (DMG; Hamburg, Germany), and Enabond SE (Micerium; Avegno (Ge), Italy), were selected according to the presence of water as the main solvent in the SE primer components. Four bottles of each adhesive system were purchased from the suppliers and only the SE primer components were used as test materials. The dental adhesives monitored and their compositions 
Table 1: Selected materials and their composition according to the information supplied in the safety data sheets and manufacturers' instructions

\begin{tabular}{lll}
\hline SE primer & Manufacturer & Composition \\
\hline Adhese SE & Ivoclar Vivadent; Schaan, Liechtenstein & $\begin{array}{l}\text { Phosphonic acid acrylate, bis-acrylamide derivative, } \\
\text { camphorquinone, water }\end{array}$ \\
Clearfil SE Bond 2 & Kuraray; Tokyo, Japan & $\begin{array}{l}\text { 2-HEMA, 10-MDP, hydrophilic aliphatic dimethacrylate, } \\
\text { camphorquinone, water }\end{array}$ \\
Contax & DMG; Hamburg, Germany & $\begin{array}{l}\text { Carboxylic acid, sodium fluoride, water } \\
\text { Enabond SE }\end{array}$ \\
\hline 2-HEMA, 2-hydroxyethyl methacrylate; 10-MDP, 10-methacryloyloxydecyl dihydrogen phosphate
\end{tabular}

are listed in Table 1. Storage, experimental part, and data evaluation were performed in the Dental Clinic of the Department of Surgical and Diagnostic Sciences at the University of Genova, Italy.

\section{Storage}

During the storage period of 6 months, the SE adhesives were kept at $4^{\circ} \mathrm{C}$ in a refrigerator. To simulate clinical usage, we removed the primer bottles from the refrigerator on a daily basis and exposed to an ambient temperature $\left(20-25^{\circ} \mathrm{C}\right)$ for 8 hours, before storing them back to the refrigerator.

\section{pH Measurements}

For $\mathrm{pH}$ measurements a microprocessor-based $\mathrm{pH} /$ temperature meter with a nominal accuracy of $\pm 0.01 \mathrm{pH}$ and $\pm 0.4^{\circ} \mathrm{C}(\mathrm{HI}-8424$ Hanna Instruments, Woonsocket, Rhode Island, United States) was used, equipped with a semi-micro electrode (HI-1330B) and a temperature probe (HI-7662) for automatic temperature compensation. Before use, the instrument was calibrated using two buffered solutions provided with the $\mathrm{pH}$ meter $(\mathrm{pH} 7.01$ and $\mathrm{pH}$ 4.01). For each $\mathrm{pH}$ measurement, the electrode and probe were submerged into the specimen vials to be tested, cleaned after each measurement and stored according to manufacturer instructions.

The $\mathrm{pH}$ measurements were performed daily, with the exception of the festive days for 6 months from June 2020 to November 2020. Four readings per day $(n=4)$, with an interval of approximately 2 hours, were made for each SE primer solution and they were averaged and considered as daily value for statistical analysis. During the monitoring period (22 weeks, namely, 110 days), 440 measurements have been done for each group (meaning 110 averaged daily value for each SE primer). The first measurement of each group was performed immediately after being unpacked and was considered as the respective initial $\mathrm{pH}$ value, hence, baseline for the analysis of the present study.

\section{Statistical Analysis}

Statistical methods used to assess the change over time of $\mathrm{pH}$ values of each product are analysis of variance (one-way ANOVA) and Pearson's product moment correlation coefficient (PMCC). A significance level of $5 \%$ was adopted in all tests. Homoscedastic distribution of data was assessed using the Kolmogorov-Smirnov test. The software used for the analysis was the IBM SPSS Statistics for iOS, Version 25.0 (IBM Corp., Armonk, New York, United States).

\section{Results}

The baseline $\mathrm{pH}$ values that were recorded prior to the mean value of everyday recording were Adhese SE 1.70, Clearfil SE 1.73,
Contax Primer 1.21, and Enabond SE 1.80. The average $\mathrm{pH}$ value of four repetitions $(n=4)$ at baseline (day one) was for each material the mean of overall $\mathrm{pH}$ measurements and standard deviation has been calculated: Contax Primer had the lowest mean $\mathrm{pH}$ value $1.20( \pm 0.01)$ and Enabond SE had the highest one $1.80( \pm 0.01)$. The mean $\mathrm{pH}$ values of Adhese SE and Clearfil SE were approximately the same, $1.70( \pm 0.01)$ and $1.72( \pm 0.01)$, respectively.

Mean $\mathrm{pH}$ values, $95 \%$ confidence interval $(\mathrm{Cl})$, linear trends as well as PMCC and one-way ANOVA are represented in Figure 1. One-way ANOVA did not detect any significant change of the mean $\mathrm{pH}$ values of all measurements over time when considering the $\mathrm{pH}$ values of each product: Adhese SE $(p=0.261)$, Clearfil SE Bond $2(p=0.380)$, Contax $(p=0.281)$, Enabond SE $(p=0.597)$. Moreover, the correlation study (time vs $\mathrm{pH}$ ) detected negligible correlations for each product: Adhese SE $(r=0.108)$, Clearfil SE Bond $2(r=0.084)$, Contax $(r=0.104)$, Enabond SE $(r=0.051)$. Homoscedastic distribution of data using the Kolmogorov-Smirnov test reported that each product was normally distributed: Adhese SE $(p=0.179)$, Clearfil SE Bond $2(p=0.149)$, Contax $(p=0.174)$, Enabond SE ( $p=0.188)$.

Based on the aim and objectives of the study, no statistical inference was observed, as the study is merely descriptive.

\section{Discussion}

In daily practice the clinicians apply SE adhesive strategy being aware of the known $\mathrm{pH}$ value of the selected SE adhesive and of the corresponding interaction with enamel and dentin. Morphological studies demonstrated that enamel etching pattern and the degree of demineralization and interaction with dentin are correlated with the acidity of the SE primers. ${ }^{1,11-13}$ This implies that it is reasonable to speculate that a possible variation of the $\mathrm{pH}$ during shelf-life may affect the conditioning pattern and bonding performance on dental substrates. ${ }^{14}$

Based on the experimental design and the findings of the present study, storage duration and conditions did not influence the $\mathrm{pH}$ value of the tested SE primers. Although a 2-year shelf-life is commonly recommended for SE adhesives, in the current study, the testing period was limited to 6 months reflecting the actual clinical conditions. ${ }^{15}$ As these adhesives are consumed at a fast rate by most clinicians, a longer storage time has been considered clinically not corresponding to real life conditions. ${ }^{15}$

No significant $\mathrm{pH}$ differences were identified in any SE primers as a function of time. This leads to rejection of the first null hypothesis that the $\mathrm{pH}$ of the tested materials changes during the storage period. The current study, however, found fluctuations in the $\mathrm{pH}$ for all evaluated SE adhesives during recording period. It is worth mentioning that in multiple $\mathrm{pH}$ measurements realistic 

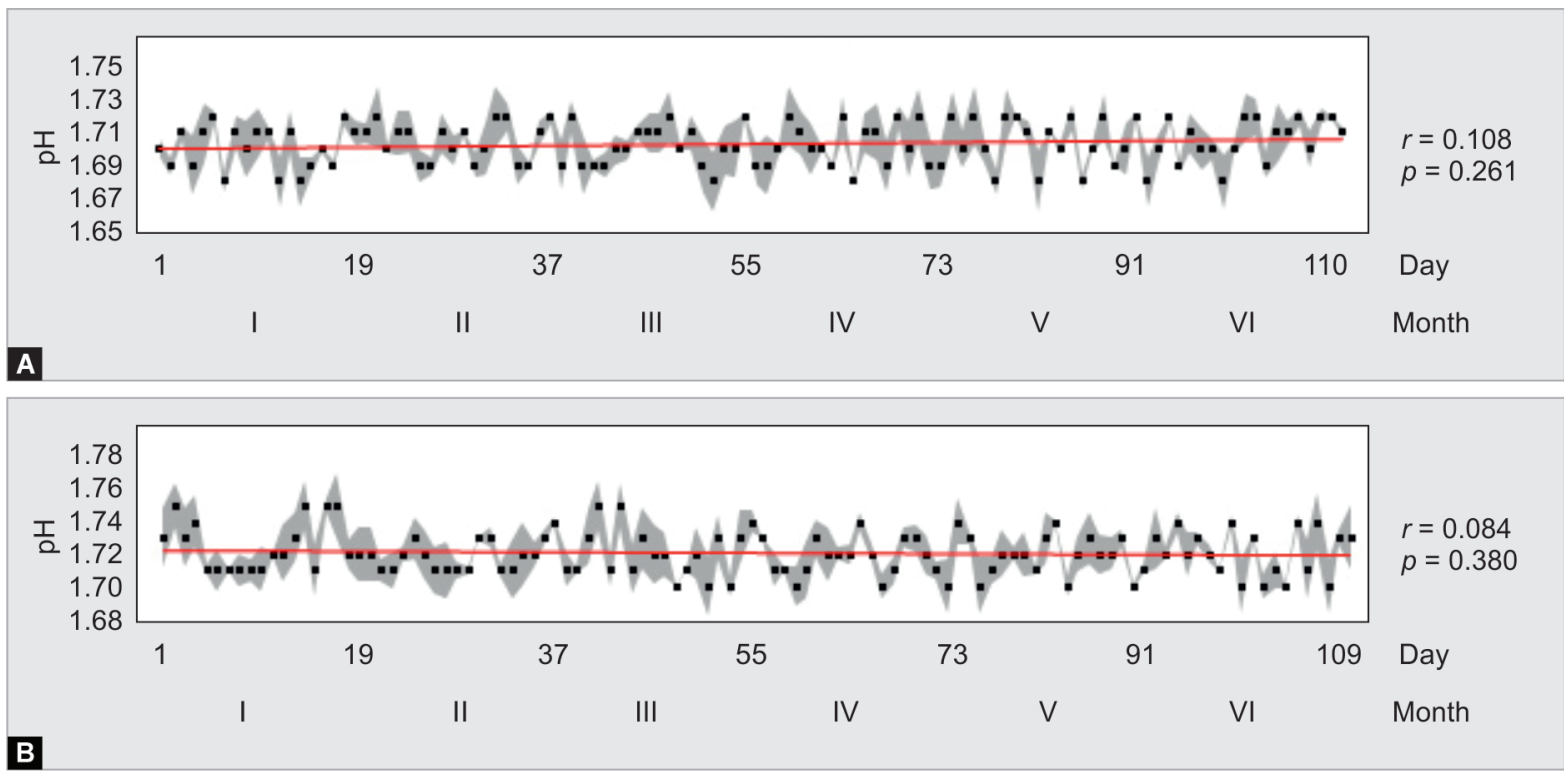

B
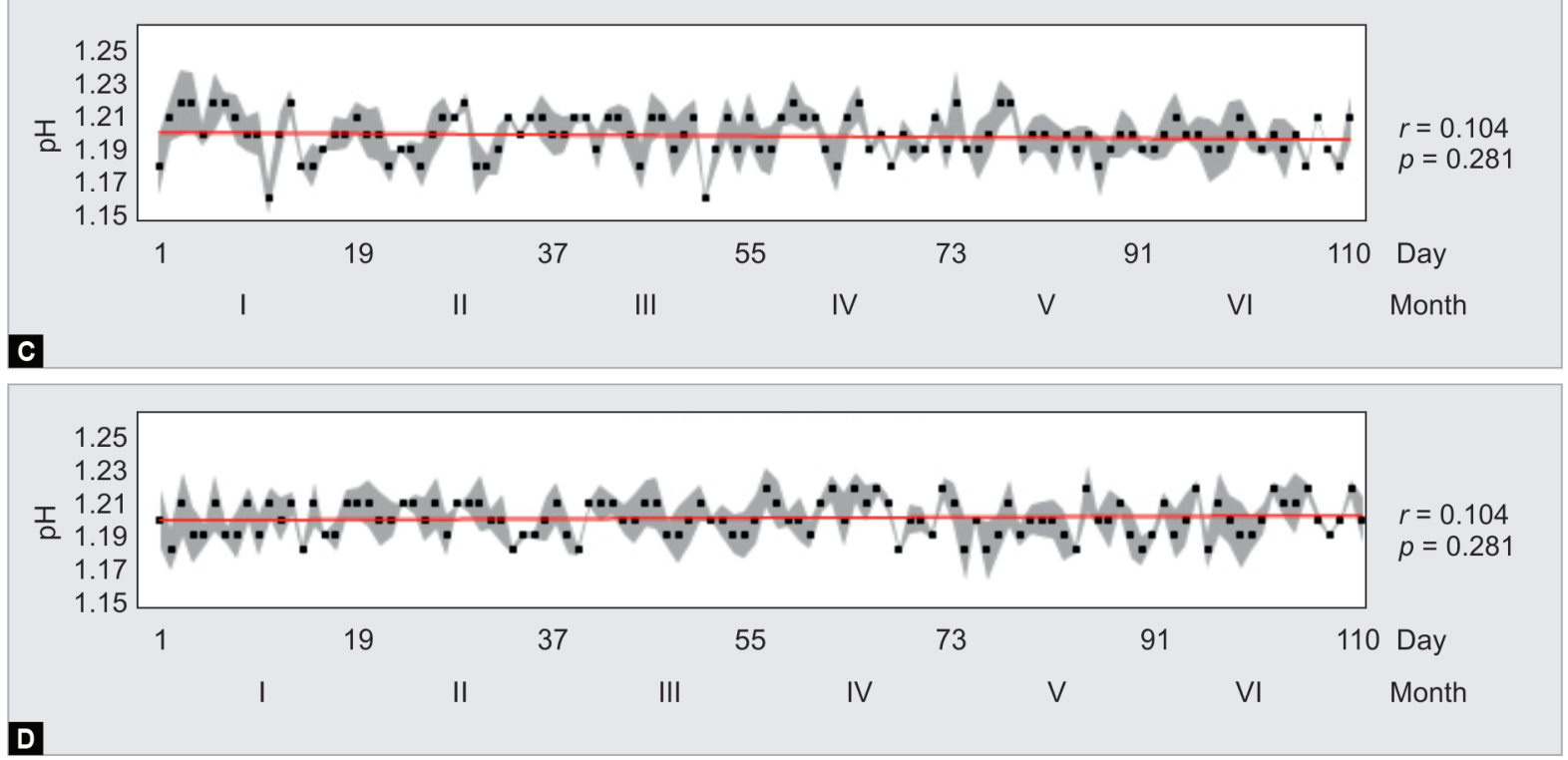

Figs 1 A to D: Mean pH values $\pm 95 \% \mathrm{Cl}$ and PMCC of (A) Adhese SE; (B) Clearfil SE Bond 2; (C) Contax; (D) Enabond SE. One-way ANOVA p-value and PMCC $r$ are reported for each product

accuracies of between \pm 0.03 and $\pm 0.05 \mathrm{pH}$ units can be achieved even assuming adequate temperature compensation, with a well calibrated, properly cleaned, and stored electrode connected to an accurate $\mathrm{pH}$ measuring instrument. ${ }^{16}$ Variations in measurement values have been observed in accurate $\mathrm{pH}$ meter and are related to several factors, such as limitations inherent in the electrode membrane, in the two-point calibration and temperature probe. ${ }^{17}$ Despite that apparent limitation of the $\mathrm{pH}$ measurement technology, $\mathrm{pH}$ deviations to the second decimal remaining close to the theoretical values are considered acceptable.

Moreover, despite the different formulations, insignificant mean $\mathrm{pH}$ variations have been observed between the SE primers during storage time. Therefore the second null hypothesis, which claims that the $\mathrm{pH}$ variation during storage period differs between the tested materials, should be rejected as well.
It is worth to mention that the Safety Data Sheet (Section 9: Physical and chemical properties) of the investigated materials, with the exception of Enabond $\mathrm{SE}$, does not provide precise data about the $\mathrm{pH}$; therefore, any direct comparison with the information provided by the manufactured would be misleading. Moreover, to date no scientific data about any possible $\mathrm{pH}$ variation of $\mathrm{SE}$ adhesive primers during shelf-life are available.

Water-free (ethanol- or acetone-based) SE priming solutions were not included in this study, due to different volatility and dielectric constant of these solvents, which influence the dissociation behavior of acids. ${ }^{6}$ The SE adhesives included in the study were water-based primers. This type of primers usually contain $30-40 \%$ water, which ionizes the acidic functional monomers that attack the apatitic crystalline structure during conditioning. ${ }^{11,18} \mathrm{~A}$ possible evaporation of the solvent during storage time and 
intermittent storage temperature or a hydrolytic degradation of the acidic monomers and co-monomers may change the original formulations leading to $\mathrm{pH}$ changes. ${ }^{9,10}$ Nevertheless, based on the results of the present study, it can be assumed that the extent of these phenomena should be limited, since the $\mathrm{pH}$ was not changed. Consequently, we may assume that the reactivity of the primers, regarding the demineralization capacity, at least, is not changed.

Accumulated evidence is showing that when the adhesives' shelf-life was tested by accelerated aging procedures, methacrylate monomers undergo rapid hydrolysis under acidic aqueous conditions. ${ }^{10}$ When water is mixed with the acidic monomers, a considerable amount of methacrylates is already decomposed by progressive acid-catalyzed hydrolysis of the ester bonds in the methacrylate monomers by water during the guaranteed shelf-life, especially if the material is stored under inadequate conditions. ${ }^{11}$ Storage duration and conditions, such as temperature, which normally accelerates the degradation processes, greatly influence the hydrolytic stability. ${ }^{10}$ However, in a previous study of Nishiyama et al., the authors demonstrated that hydrolysis of functional methacrylate monomers occurs despite conservation carried out according to the manufacturers' instructions..$^{15}$ The hydrolysis of the adhesive monomers completely changes the chemical composition and their physical properties. ${ }^{10}$

However, in our study design, direct correlation between degradation phenomena and $\mathrm{pH}$ stability was not detectable.

The experimental set-up used in this study had several limitations that deserve some comments. As already mentioned in the present investigation, only water-based SE priming solutions were tested. The results may have been different if SE primers with more volatile solvents, such as ethanol or acetone-based systems, had been investigated. Therefore, ideally, also ethanolor acetone-based SE primers should be included in a foreseeable future study, to fully assess the suggested results. In addition, measuring the $\mathrm{pH}$ only is not sufficient to monitor the hydrolytic degradation of functional methacrylate monomers under acidic aqueous conditions. A lack of data assessing a direct correlation between degradation phenomena of functional monomers and $\mathrm{pH}$ stability encourages future investigations on this matter. The study limitations include the fact that an absolute worst case scenario was tested, by leaving the samples to an ambient temperature $\left(20-25^{\circ} \mathrm{C}\right)$ for 8 hours on a daily basis. These limitations should be considered when interpreting the results.

\section{CONCLUSION}

Within the experimental limitations of this study, it is possible to conclude that the storage time under appropriate conditions does not affect primers' $\mathrm{pH}$ values of two-bottle SE adhesives. Whereas the $\mathrm{pH}$ stability over time of SE priming solutions is not influenced by different formulations.

\section{Acknowledgments}

Authors wish to thank all manufacturers for the generous donation of materials. Special gratitude is extended to Prof. George Eliades from the University of Athens, Greece and Prof. Vassilios Kaitsas from the University of Genoa, Italy, for data evaluation and valuable discussion.

\section{References}

1. Tay FR, Pashley DH. Aggressiveness of contemporary self-etching systems. I: depth of penetration beyond dentin smear layers. Dent Mater 2001;17(4):296-308. DOI: 10.1016/s0109-5641(00)00087-7.

2. Van Meerbeek B, Yoshihara K, Yoshida Y, et al. State of the art of self-etch adhesives. Dent Mater 2011;27(1):17-28. DOI: 10.1016/j. dental.2010.10.023.

3. Van Meerbeek B, De Munck J, Yoshida Y, et al. Buonocore memorial lecture. Adhesion to enamel and dentin: current status and future challenges. Oper Dent 2003;28(3):215-235. PMID: 12760693.

4. Moszner N, Salz U, Zimmermann J. Chemical aspects of selfetching enamel-dentin adhesives: a systematic review. Dent Mater 2005;21(10):895-910. DOI: 10.1016/j.dental.2005.05.001.

5. Salz U, Mücke A, Zimmermann J, et al. pKa value and buffering capacity of acidic monomers commonly used in self-etching primers. J Adhes Dent 2006;8(3):143-150. PMID: 16830660.

6. Iwasa M, Tsubota K, Shimamura $Y$, et al. pH changes upon mixing of single-step self-etching adhesives with powdered dentin. J Adhes Dent 2011;13(3):207-212. DOI: 10.3290/j.jad.a19240.

7. Van Landuyt KL, Snauwaert J, De Munck J, et al. Systematic review of the chemical composition of contemporary dental adhesives. Biomaterials 2007;28(26):3757-3785. DOI: 10.1016/j. biomaterials.2007.04.044.

8. Koshiro K, Sidhu SK, Inoue S, et al. New concept of resin-dentin interfacial adhesion: the nanointeraction zone. J Biomed Mater Res B Appl Biomater 2006;77(2):401-408. DOI: 10.1002/jbm.b.30450.

9. Nishiyama N, Suzuki K, Yoshida H, et al. Hydrolytic stability of methacrylamide in acidic aqueous solution. Biomaterials 2004;25(6):965-969. DOI: 10.1016/s0142-9612(03)00616-1.

10. Salz U, Zimmermann J, Zeuner $F$, et al. Hydrolytic stability of selfetching adhesive systems. J Adhes Dent 2005;7(2):107-116. PMID: 16052759.

11. Lima GdaS, Ogliari FA, da Silva EO, et al. Influence of water concentration in an experimental self-etching primer on the bond strength to dentin. J Adhes Dent 2008;10(3):167-172. PMID: 18652264.

12. Moura SK, Pelizzaro A, Dal Bianco K, et al. Does the acidity of selfetching primers affect bond strength and surface morphology of enamel? J Adhes Dent 2006;8(2):75-83. PMID: 16708718.

13. Breschi L, Gobbi P, Mazzotti G, et al. High resolution SEM evaluation of dentin etched with maleic and citric acid. Dent Mater 2002;18(1):26-35. DOI: 10.1016/s0109-5641(01)00017-3.

14. Kenshima S, Francci C, Reis A, et al. Conditioning effect on dentin, resin tags and hybrid layer of different acidity self-etch adhesives applied to thick and thin smear layer. J Dent 2006;34(10):775-783. DOI: 10.1016/j.jdent.2006.03.001.

15. Nishiyama N, Tay FR, Fujita K, et al. Hydrolysis of functional monomers in a single-bottle self-etching primer--correlation of 13C NMR and TEM findings. J Dent Res 2006;85(5):422-426. DOI: $10.1177 / 154405910608500505$.

16. Cheng KL, Zhu DM. On calibration of $\mathrm{pH}$ meters. Sensors 2005;5(4):209-219. DOI: 10.3390/s5040209.

17. Meinrath G, Spitzer P. Uncertainties in determination of $\mathrm{pH}$. Microchim Acta 2000;13(3-4):155-168. DOI: 10.1007/s006040070005.

18. Pashley DH, Carvalho RM, Tay FR, et al. Solvation of dried dentin matrix by water and other polar solvents. Am J Dent 2002;15(2):97-102. PMID: 12092999. 